\title{
Recuperação de pasto de capim-braquiária com correção e adubação de solo e estabelecimento de leguminosas
}

\author{
Recovery of pasture braquiaria grass with correction and fertilizing soil and \\ establishment of legumes
}

\author{
GAMA, Tatiana da Costa Moreno ${ }^{1 *}$; VOLPE, Edimilson ${ }^{1}$; LEMPP, Beatriz ${ }^{2}$; \\ GALDEIA, Elaine Costa ${ }^{2}$
}

\begin{abstract}
${ }^{1}$ Agência de Desenvolvimento Agrário e Extensão Rural de Mato Grosso do Sul, Centro de Pesquisa de Capacitação da AGRAER, Departamento de Forragicultura, Campo Grande, Mato Grosso do Sul, Brasil. ${ }^{2}$ Universidade Federal da Grande Dourados, Programa de Pós-Gaduação em Agronomia, Dourados, Mato Grosso do Sul, Brasil

*Endereço para correspondência: tmorenogama@ hotmail.com
\end{abstract}

\section{RESUMO}

Objetivou-se determinar a melhor combinação para recuperação de pasto de Urochloa decumbens cv. Basilisk utilizando sete tratamentos que constaram do capim-braquiária sem intervenção (sem correção de solo e adubação); do capim-braquiária adubado com fósforo $(\mathrm{P})$ e potássio $(\mathrm{K})$ sem nitrogênio $(\mathrm{N})$; do capim-braquiária adubado com $\mathrm{P}, \mathrm{K}$ e N ; e dos consórcios com: Arachis pintoi + Stylosanthes cv. Campo Grande; Stylosanthes cv. Campo Grande; Calopogonium mucunoides + Neonotonia wightii e N. wightii. O delineamento experimental foi em blocos ao acaso com quatro repetições. Foram realizados seis cortes por tratamento para verificação do acúmulo de biomassa, composição morfológica e análises de proteína bruta, fibra em detergente neutro e ácido, lignina e digestibilidade in vitro. A correção do solo e a adubação com P e K proporcionaram acúmulo de forragem significativamente maior que o capim-braquiária sem intervenção. Entretanto, os maiores acúmulos de forragem foram obtidos nos consórcios com mistura de leguminosas forrageiras, que não diferiram do capim-braquiária adubado com $\mathrm{N}$, demonstrando a maior viabilidade de utilização dos consórcios com mais de uma espécie de leguminosa. As folhas de $U$. decumbens apresentaram, de modo geral, melhor valor nutritivo quando consorciadas com leguminosas. A utilização das leguminosas herbáceas na recuperação de pasto de capimbraquiária degradados sem utilização de adubos nitrogenados mostra-se viável, pois favorece o acúmulo de forragem e a qualidade da gramínea, com destaque para a mistura de leguminosas. A adubação nitrogenada aumenta a produtividade da gramínea, mas proporciona menor razão folha/colmo e, seus componentes fibrosos apresentam baixa digestibilidade da forragem.

Palavras-chave: composição química, consorciação, degradação, digestibilidade, sustentabilidade

\section{SUMMARY}

This study aimed to determine the best combination for recovery pasture Urochloa decumbens cv. Basilisk using seven treatments which consisted of braquiaria grass without intervention (without correction of soil and fertilizer), the braquiaria grass fertilized with phosphorus (P) and potassium (K) without nitrogen $(\mathrm{N})$, the braquiaria grass fertilized with $\mathrm{P}, \mathrm{K}$ and N, and consortia with: Arachis pintoi + Stylosanthes cv. Campo Grande; Stylosanthes cv. Campo Grande; Calopogonium mucunoides + Neonotonia wightii and N. wightii. The experimental design was a randomized block with four replications. Six cuts by treatment were performed to verify the biomass accumulation, morphological composition and analysis of crude protein, neutral detergent fiber and acid, lignin and in vitro digestibility. The liming and fertilization with $\mathrm{P}$ and $\mathrm{K}$ provided 
forage accumulation significantly higher of the braquiaria grass without intervention. However, the highest accumulation was obtained in consortia with mixture of forage legumes, which did not differ from braquiaria grass fertilized with $\mathrm{N}$, demonstrating the feasibility of using the largest consortia with more than one species of legume. The leaves of $U$. decumbens showed, in general, better nutritional value when intercropped with legumes. The use of herbaceous legumes in pasture recovery braquiaria grass degraded without the use of nitrogen fertilizers is not only viable, it favors the accumulation of forage and quality of the grass, especially the mixture of legumes. Nitrogen fertilization increases the productivity of the grass, but provides a lower leaf / stem ratio and its components have a low fiber digestibility of forage.

Keywords: chemical composition, degradation, digestibility, legume intercrop, sustainability

\section{INTRODUÇÃO}

A degradação dos pastos cultivados no Cerrado é um dos principais problemas da agropecuária, acarretando graves consequências ambientais e econômicas. Os trabalhos que investigaram correção e adubação do solo com gramíneas tropicais, de maneira geral, têm mostrado respostas, principalmente para o fósforo e o nitrogênio, cuja intensidade é variável em função das condições edafoclimáticas e das técnicas associadas (PACIULLO et al., 2003).

Oliveira et al. (2010) estudando os efeitos de combinações de nitrogênio com enxofre na relação de nutrientes do capim-braquiária em degradação verificaram baixa relação nitrogênio:enxofre na ausência da aplicação do nitrogênio, comprovando que a maior deficiência nutricional no capim-braquiária em recuperação é de nitrogênio.

Portanto, tem se buscado outras técnicas de manejo de pastagens para o aumento dos atuais índices encontrados nas monoculturas de pastagens de gramíneas forrageiras, entre elas, consorciações com leguminosas forrageiras. As leguminosas forrageiras, ao realizar a fixação biológica do $\mathrm{N}$ atmosférico e contribuir com a produção animal, têm importância crucial, tanto para o aumento da produtividade, quanto para a sustentabilidade das pastagens (BARCELLOS et al., 2008). Contudo, a dificuldade de implantação e baixa persistência de diversas espécies de leguminosas em pastagens consorciadas com gramíneas são aspectos limitantes. Uma provável solução seria a utilização de mistura de leguminosas, pois este quando comparados ao uso de apenas uma única espécie de leguminosa pode apresentar maiores mecanismos de sobrevivência dentre de um consórcio. O uso de mais de uma espécie de leguminosa em consórcio com gramínea procura combinar diferentes estratégias de adaptação e persistência, como maior número de mecanismos morfológicos, fisiológicos e fenológicos, e de tolerância a pragas e doenças.

Assim, o objetivo do presente trabalho consistiu em determinar através da realização de calagem, adubação química do solo e utilização de espécies de leguminosas em consórcio com Urochloa decumbens cv. Basilisk a melhor combinação para recuperação de pastagem em degradação, em ambiente de Cerrado.

\section{MATERIAL E MÉTODOS}

O trabalho foi realizado em Campo Grande, MS, no Centro de Pesquisa e Capacitação da Agência de Desenvolvimento Agrário e extensão Rural de Mato Grosso do Sul (CEPAER), localizada a $20^{\circ} 28^{\prime}$ de latitude Sul e $55^{\circ} 40^{\prime}$ de longitude Oeste, com altitude 
média de $520 \mathrm{~m}$, no período de janeiro de 2008 a outubro de 2010.

O padrão climático da região é descrito, pela classificação do Köppen, na faixa de transição entre Cfa e Aw tropical úmido. A precipitação média anual é de
$1.500 \mathrm{~mm}$, sendo o período de verão quente e chuvoso, e abrange os meses de outubro a março (Figura 1), enquanto que o período frio é seco, sem chuvas, e incluí os meses de abril a setembro.

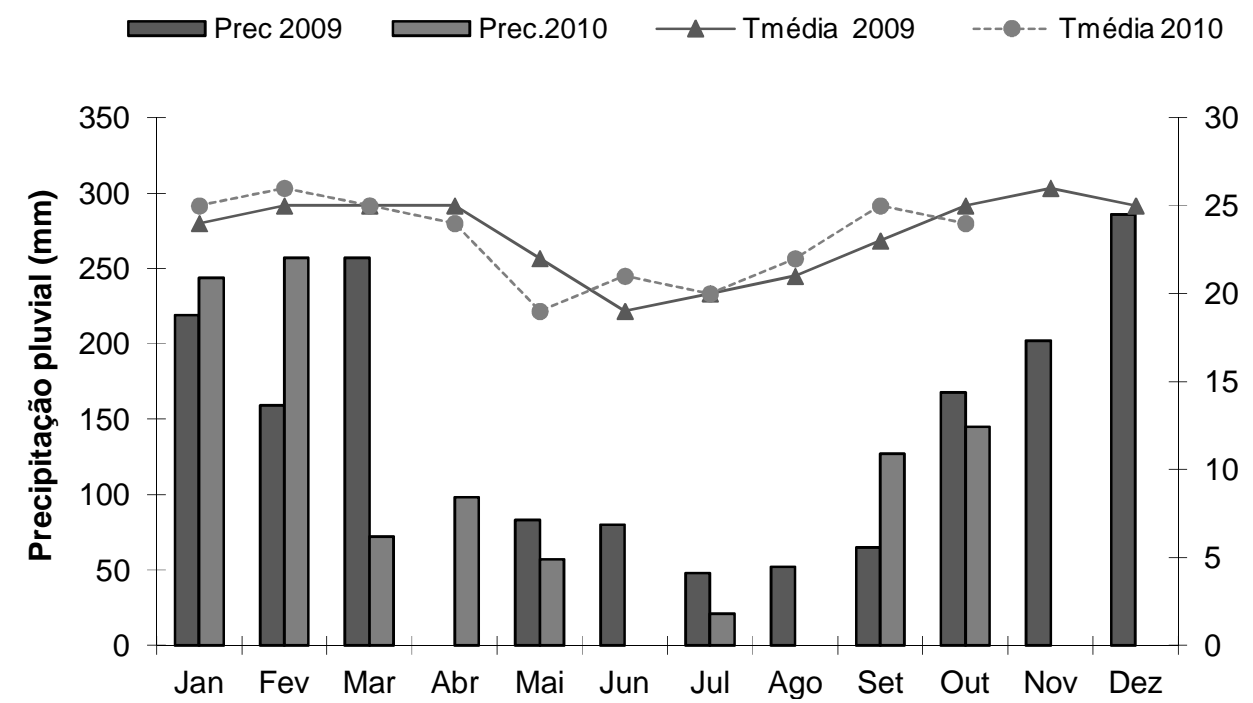

Figura 1. Precipitação pluvial mensal $(\mathrm{mm})$ e Temperatura média mensal $\left({ }^{\circ} \mathrm{C}\right)$ durante $\mathrm{o}$ período experimental (Estação meteorológica do CEPAER/CEMTEC - Campo Grande/MS)

A área experimental total, equivalente a 0,5 ha, foi utilizada, aproximadamente, por 10 anos com o monocultivo de Urochloa decumbens (capimbraquiária). O solo é Latossolo Vermelho distrófico, de textura argilosa e apresentou as seguintes características químicas no início do período experimental: $\mathrm{pH}$ (água) $=5,45 ; \mathrm{P}$ disponível $=2,51 \mathrm{mg} / \mathrm{dm}^{3} ; \mathrm{K}$ disponível $=0,36 \mathrm{mg} / \mathrm{dm}^{-3} ; \mathrm{Ca}=2,40 ; \mathrm{Mg}=1,05$; $\mathrm{Al}=0,29, \mathrm{H}+\mathrm{Al}=4,76, \mathrm{SB}=3,46 \mathrm{e}$ $\mathrm{CTC}=8,22 \mathrm{cmolc} / \mathrm{dm}^{3} ; \mathrm{MO}=$ $30,7 \mathrm{~g} / \mathrm{dm}^{3}$ e $\mathrm{V}=42 \%$.

As leguminosas foram implantadas em dezembro de 2004 (VOLPE et al., 2008). Em fevereiro de 2008 efetuou-se a reimplantação de algumas leguminosas, com preparo de solo com grade niveladora e manejo das leguminosas, como: cortes, semeaduras e replantios. A leguminosa herbácea Arachis pintoi cv. Belmonte, implantada por mudas (01 muda por $\left.\mathrm{m}^{2}\right)$, + Stylosanthes capitata e $S$. macrocephala - Estilosantes Campo Grande (mix araquis - mistura de leguminosas) substituíram o tratamento com o Calopogonium mucunoides calopogônio e no tratamento com o $S$. guianensis - Estilosantes cv. Minerão, onde poucas plantas persistiram, foram semeadas a mistura de calopogônio + Neonotonia wightii - soja perene ( $\mathrm{mix}$ soja $\mathrm{p}$ - mistura de leguminosas).

No presente estudo avaliou-se a $U$. decumbens $\mathrm{cv}$. Basilisk sem correção de solo e adubação, com adubação e em consórcio com leguminosas. Os tratamentos consistiram de parcelas com 
o capim-braquiária sem intervenção ( sem correção de solo e adubação) e de mais seis parcelas com intervenções presentes. As seis intervenções foram: capim-braquiária com correção de solo e adubação com fósforo $(\mathrm{P})$ e potássio (K) sem nitrogênio; com $\mathrm{P}, \mathrm{K}$ e 100kg.ha.ano ${ }^{-1}$ de nitrogênio; em consórcio com A. pintoi cv. Belmonte + Stylosantes cv. Campo Grande (mix araquis); com Stylosantes cv. Campo Grande; com C. mucunoides $+N$. wightii (mix soja p) e com N. wightii (soja perene).

$\mathrm{O}$ delineamento experimental utilizado foi de blocos casualizados, devido à presença de níveis de declividade na área experimental, conduzido em esquema de parcelas subdivididas, tendo nas parcelas os tratamentos e nas subparcelas as épocas de corte, com quatro repetições. As parcelas foram de $05 \times 10 \mathrm{~m}$, com área útil de $36 \mathrm{~m}^{2}$. Todos os tratamentos, exceto o capimbraquiária sem intervenção, sofreram correção de solo, com calcário dolomítico visando atingir saturação por bases de $60 \%$ no solo, e adubação de $100 \mathrm{~kg} / \mathrm{ha}$ de $\mathrm{P}_{2} \mathrm{O}_{5}$ e $\mathrm{K}_{2} \mathrm{O}$ no período de reimplantação do experimento.

Os cortes da forragem para as avaliações ocorreram entre janeiro de 2009 a outubro de 2010, a intervalos de dois meses nas águas e de cinco na seca. A amostragem da forragem foi efetuada em área útil de $04 \mathrm{~m}^{2}$ por parcela e ocorreu quando o capim atingiu altura aproximada de $40 \mathrm{~cm}$, deixando resíduo de aproximadamente $10 \mathrm{~cm}$ (SILVA \& NASCIMENTO JÚNIOR, 2007).

Após cada corte ou amostragem da forragem foram introduzidos animais na área experimental com objetivo de uniformização das parcelas experimentais. As vacas foram retiradas da área experimental aproximadamente após sete dias, quando o resíduo de forragem era próximo a $10 \mathrm{~cm}$ do solo.
Após pesagem do material verde amostrado em cada avaliação experimental foram retiradas duas subamostras de cada tratamento, uma para a estimativa do acúmulo total de biomassa seca (aproximadamente 10\% do total colhido) e outra na mesma proporção para separação manual dos componentes morfológicos da gramínea (lâmina foliar, colmo e bainha verdes, material senescente). Nas intervenções em consórcio também foi realizada a estimativa da composição botânica, por meio da separação manual dos componentes gramínea e leguminosa.

Após a separação morfológica e botânica, os componentes foram pesados, secos em estufa de circulação forçada de ar a $65^{\circ} \mathrm{C}$, por 72 horas, e novamente pesados. A proporção de cada componente morfológico e botânico foi expressa em porcentagem da biomassa seca total.

Com base nos dados obtidos estimaramse as seguintes características: acúmulo de biomassa, proporção da composição botânica dos consórcios, razão folha/colmo das gramíneas.

As lâminas foliares da gramínea, material comestível das leguminosas foram analisadas quanto aos teores de matéria seca (MS), fibra em detergente neutro (FDN), fibra em detergente ácido (FDA), lignina em permanganato de potássio, proteína bruta $(\mathrm{PB}) \mathrm{e}$ digestibilidade in vitro da MS (DIVMS) de acordo com as técnicas descritas por Silva \& Queiroz (2002).

Para realização da análise estatística, utilizou-se a média dos valores obtidos durante os dois anos do experimento. Os dados foram submetidos à análise de variância em delineamento em blocos casualizados e em esquema de parcela subdivididas com o objetivo de estimar os resíduos associados às parcelas $\mathrm{e}$ subparcelas. As interações significativas entre os fatores foram desdobradas. 
Todas as médias foram comparadas pelo teste de Scott-Knott a 5\% de probabilidade, por meio do programa computacional estatístico SAEG 9.1 (RIBEIRO JÚNIOR, 2001).

\section{RESULTADOS E DISCUSSÃO}

Ocorreu interação significativa entre as fontes de variação, épocas de avaliação e tratamento, para o acúmulo de biomassa verde, provavelmente devido ao comportamento diferenciado dos tratamentos nas épocas de avaliação e vice-versa. (Tabela 1). Além das variações de temperatura e fotoperíodo, a estacionalidade das chuvas não permite a produção uniforme de forragem durante $\mathrm{o}$ ano. Portanto, em períodos favoráveis como o verão, o capim-braquiária apresenta melhor rendimento forrageiro, e como o obtido neste trabalho, ocorre também maior acúmulo de lâmina foliar.

Tabela 1. Acúmulo de biomassa verde comestível (lâmina foliar da gramínea e leguminosas) (kg/ha) de capim-braquiária em monocultivo, adubada com nitrogênio e em consórcio com leguminosas

\begin{tabular}{|c|c|c|c|c|}
\hline \multirow{2}{*}{ Tratamentos } & \multicolumn{4}{|c|}{ Acúmulo de biomassa comestível } \\
\hline & Águas/09 & Seca/09 & Águas/10 & Seca/10 \\
\hline capim-braquiária sem intervenção & $3.819^{\mathrm{Ba}}$ & $1.297^{\mathrm{Bb}}$ & $4.174^{\mathrm{Ca}}$ & $827^{\mathrm{Bb}}$ \\
\hline capim-braquiária sem $\mathrm{N}$ & $3.137^{\mathrm{Bb}}$ & $1.382^{\mathrm{Bc}}$ & $5.553^{\mathrm{Ba}}$ & $1.079^{\mathrm{Bd}}$ \\
\hline capim-braquiária com $\mathrm{N}$ & $4.695^{\mathrm{Ab}}$ & $1.540^{\mathrm{Bc}}$ & $7.824^{\mathrm{Aa}}$ & $956^{\mathrm{Bd}}$ \\
\hline capim-braquiária + estilosantes CG & $4.679^{\mathrm{Ab}}$ & $1.375^{\mathrm{Bc}}$ & $6.247^{\mathrm{Ba}}$ & $1.059^{\mathrm{Bd}}$ \\
\hline capim-braquiária + mix soja p. & $5.000^{\mathrm{Ab}}$ & $1.954^{\mathrm{Ac}}$ & $7.521^{\mathrm{Aa}}$ & $1.522^{\mathrm{Ac}}$ \\
\hline capim-braquiária + soja p. & $4.173^{\mathrm{Bb}}$ & $1.448^{\mathrm{Bc}}$ & $7.755^{\mathrm{Aa}}$ & $1.066^{\mathrm{Bd}}$ \\
\hline capim-braquiária + mix arachis & $5.056^{\mathrm{Aa}}$ & $2.088^{\mathrm{Ab}}$ & $6.870^{\mathrm{Aa}}$ & $1.445^{\mathrm{Ab}}$ \\
\hline Média das Épocas & $4.365^{\mathrm{b}}$ & $1.584^{\mathrm{c}}$ & $6.564^{\mathrm{a}}$ & $1.140^{\mathrm{d}}$ \\
\hline $\mathrm{CV}(\%)$ & & $14,65^{*}$ & $16,67 * *$ & \\
\hline
\end{tabular}

Médias seguidas de letras maiúsculas nas colunas e minúsculas nas linhas não diferem entre si pelo teste Scott-Knott $(\mathrm{P}>0,05)$.

*CV (coeficiente de variação) dos tratamentos, **CV das épocas.

N, estilosantes CG, mix soja p. e mix arachis: Nitrogênio, Stylosantes cv. Campo Grande, Calopogonium mucunoides + Neonotonia. Wightii, Arachis pintoi cv. Belmonte + Stylosantes cv. Campo Grande, respectivamente.

A superioridade para maioria dos tratamentos na segunda época das águas pode ser explicada pela alta precipitação pluvial ocorrida no final de 2009 e início de 2010 (Figura 1), favorecendo assim o melhor desenvolvimento das plantas, e provavelmente ao maior controle nos intervalos de corte e no manejo do pastejo animal pós-corte ou também a uma maior contribuição das leguminosas pela de fixação biológica de N.

$\mathrm{O}$ efeito isolado da calagem e da adubação com $\mathrm{P}$ e $\mathrm{K}$, como no capimbraquiária sem $\mathrm{N}$, proporcionou acúmulo de biomassa verde significativamente maior que o capim-braquiária sem intervenção, sendo que o maior acúmulo foi obtido nos consórcios com mix de leguminosas, que não diferiram do capim-braquiária adubado com $\mathrm{N}$, 
demostrando a maior viabilidade de utilização dos consórcios com mais de uma espécie de leguminosa.

Nos dois períodos das águas estudados os consórcios com essas leguminosas se destacaram em relação às demais, principalmente com relação à persistência da soja perene ao longo dos anos de avaliação. Na revisão de Barcellos et al. (2008), os autores destacam a importância e a necessidade de que a leguminosa seja capaz de co-existir com a gramínea no pasto, com a finalidade de manter a produtividade dos capins ao longo do tempo.

Dentre as leguminosas avaliadas, a soja perene manteve-se produtiva ao longo dos anos de utilização desde a sua primeira implantação em 2004. Segundo Macharia et al. (2010), que estudaram o potencial das leguminosas em contribuir para melhoria da qualidade e quantidade de pastagens naturais no Quênia, esta leguminosa apresentou enrainzamento profundo, o que levou a alta resistencia a desfolha intensa. Esta resistência pode estar relacionada a localidade de suas gemas, que ficam escondidas logo abaixo da superfície do solo, conferindo maior capacidade de regeneração a essa espécie.

Segundo Volpe et al. (2008), na avaliação de estabelecimento desses mesmos consórcios as leguminosas herbáceas foram prejudicadas pelo excesso de plantas e agressividade da gramínea, apresentando desempenho inferior aos demais, com exceção do capim-braquiária sem intervenção. $\mathrm{O}$ que não persistiu durante esta fase de manutenção, evidenciando que as leguminosas conseguiram se estabelecer mesmo com o efeito da concorrência na fase de estabelecimento.

Nas épocas de seca, novamente, os consórcios com mix de leguminosas foram superiores aos demais, inclusive ao tratamento com N. Maiores acúmulos de massa foram verificados na seca de 2009 em relação à de 2010 para o capim-braquiária com $\mathrm{N}$ e no consórcio com estilosantes CG. Os resultados para o capim-braquiária adubado com $\mathrm{N}$ sugerem que não houve efeito residual deste tipo de adubação visando à manutenção da produção de uma época para outra.

Enquanto que, o menor acúmulo do consórcio com o estilosantes CG, provavelmente se deve a menor participação da leguminosa no decorrer do período experimental (Tabela 2), o mesmo fato ocorreu com o Estilosantes cv. Minerão que estava presente nos consórcios durante a fase de implantação do experimento, em 2004. Almeida et al. (2003) ao avaliarem o consórcio do capim-braquiária e $S$. guianensis também verificaram que as massas de forragem decresceram $81 \%$ e $23 \%$, respectivamente, no final do período seco quando comparadas com a média do período das águas.

De modo geral, verifica-se que os resultados obtidos estão de acordo com os obtidos por outros autores (FAGUNDES et al., 2005; FAGUNDES et al., 2006; MAGALHÃES et al., 2007) que encontraram expressivo retorno na produção de biomassa seca de forrageiras do gênero Urochloa, após tratamentos com aplicação de fertilizantes, especialmente com $\mathrm{N}$ ou a implantação de consórcio com leguminosas.

Na composição botânica dos tratamentos com leguminosas pode-se observar a participação das leguminosas (\%) no acúmulo de biomassa (Tabela 2). Houve efeito significativo da interação dos tratamentos e épocas, sobre a percentagem de gramínea e leguminosa. $\mathrm{Na}$ média dos tratamentos, os consórcios com mix de leguminosas foram superiores aos demais consórcios, 
Rev. Bras. Saúde Prod. Anim., Salvador, v.14, n.4, p.635-647 out./dez., 2013 http://www.rbspa.ufba.br ISSN 15199940

com relação ao percentual de leguminosas.

Nenhum consórcio apresentou boa quantidade de participação das leguminosas no acúmulo de biomassa. Onde, segundo Fisher et al. (1997) estimaram que a participação das leguminosas na pastagem deve estar acima de $30 \%$, para que haja maior recuperação do $\mathrm{N}$ na serrapilheira da leguminosa pela gramínea.

Tabela 2. Porcentagem de gramínea e leguminosa no acúmulo de biomassa $(\mathrm{kg} / \mathrm{ha})$ de capim-braquiária em monocultivo, adubada com nitrogênio e em consórcio com leguminosas

\begin{tabular}{lcccc}
\hline \multirow{2}{*}{ Tratamentos } & Águas/09 & Seca/09 & Águas/10 & Seca/10 \\
\cline { 2 - 5 }$\%$ gramínea \\
\cline { 2 - 5 } capim-braquiária + estilosantes CG & $78^{\mathrm{Ab}}$ & $100^{\mathrm{Aa}}$ & $97^{\mathrm{Aa}}$ & $100^{\mathrm{Aa}}$ \\
capim-braquiária + mix soja p. & $87^{\mathrm{Aa}}$ & $89^{\mathrm{Ba}}$ & $85^{\mathrm{Ca}}$ & $82^{\mathrm{Da}}$ \\
capim-braquiária + soja p. & $85^{\mathrm{Ab}}$ & $94^{\mathrm{Ba}}$ & $88^{\mathrm{Bb}}$ & $96^{\mathrm{Ba}}$ \\
capim-braquiária + mix araquis & $79^{\mathrm{Aa}}$ & $93^{\mathrm{Ba}}$ & $88^{\mathrm{Ba}}$ & $85^{\mathrm{Ca}}$ \\
Média das Épocas & $82^{\mathrm{b}}$ & $94^{\mathrm{a}}$ & $89^{\mathrm{a}}$ & $91^{\mathrm{a}}$ \\
\hline CV $(\%)$ & \multicolumn{5}{c}{$8,65^{*}$} & $\%$ leguminosa \\
\hline & $22^{\mathrm{Aa}}$ & - & $2,5^{\mathrm{Bb}}$ & - \\
\hline capim-braquiária + estilosantes CG & $13^{\mathrm{Aa}}$ & $11 \mathrm{~A}^{\mathrm{a}}$ & $15^{\mathrm{Aa}}$ & $18^{\mathrm{Aa}}$ \\
capim-braquiária + mix soja p. & $15^{\mathrm{Aa}}$ & $6^{\mathrm{Ab}}$ & $13^{\mathrm{Aa}}$ & $4^{\mathrm{Bb}}$ \\
capim-braquiária + soja p. & $21^{\mathrm{Aa}}$ & $7^{\mathrm{Aa}}$ & $12^{\mathrm{Aa}}$ & $15^{\mathrm{Aa}}$ \\
capim-braquiária + mix araquis & $18^{\mathrm{a}}$ & $06^{\mathrm{b}}$ & $11^{\mathrm{b}}$ & $09^{\mathrm{b}}$ \\
Média das Épocas & \multicolumn{5}{c}{$34,61^{*}$} & $36,67^{* *}$ \\
\hline CV $(\%)$ & & \multicolumn{4}{c}{} \\
\hline
\end{tabular}

Médias seguidas de letras maiúsculas nas colunas e minúsculas nas linhas não diferem entre si pelo teste Scott-Knott $(\mathrm{P}>0,05)$. ${ }^{*} \mathrm{CV}$ dos tratamentos, ${ }^{* *} \mathrm{CV}$ das épocas.

estilosantes CG, mix soja p. e mix arachis: Stylosantes cv. Campo Grande, Calopogonium mucunoides + Neonotonia. Wightii, Arachis pintoi cv. Belmonte + Stylosantes cv. Campo Grande, respectivamente.

Nos consórcios de capim-braquiária + estilosantes CG e capim-braquiária + soja perene verificou-se variação na percentagem de leguminosa durante as épocas do ano, o que não foi observado nos tratamentos com misturas de leguminosas. Sendo que para a soja perene a variação se deu entre período das águas e seca, tendo observado diminuição da participação desta nas épocas de seca. Já o tratamento com estilosantes CG foi prejudicado, logo após a primeira época de avaliação, devido sua baixa persistência no consórcio. Os resultados apresentados, principalmente para as épocas de seca, evidenciam a pequena participação desta leguminosa ao longo das avaliações.

É possível perceber, através dos resultados de percentagem, que os efeitos das condições climáticas afetam a produção e participação nos consórcio das leguminosas herbáceas, principalmente nos tratamentos em que não se tinha misturas (mix).

$\mathrm{O}$ aumento na proporção de leguminosa em consórcio com gramínea é almejado, mas, raramente, isso tem sido verificado para a maioria das espécies (PARIS et 
al., 2009). Como as proporções das leguminosas variaram entre as épocas de avaliação, percebe-se que nos consórcios com mix os percentuais têm se elevado com o passar do tempo, principalmente no mix soja perene com calopogônio.

No mix araquis o aumento percentual de leguminosa se deve principalmente ao estabelecimento do Arachis pintoi. Pois, como ocorreu no consórcio de capim-braquiária + estilosantes $\mathrm{CG}$, esta mesma leguminosa apresentou melhor desempenho na apenas primeira avaliação, e teve sua participação na mistura de leguminosas diminuída nas demais avaliações.

Provavelmente, o estilosantes Campo Grande, por ser uma cultivar com adaptação a solos de baixa fertilidade e com textura arenosa e média
(BARCELLOS et al., 2008; PAULINO et al., 2008), não obteve bom estabelecimento na área experimental e teve sua capacidade competitiva afetada negativamente dentro dos consórcios com o capim-braquiária.

Com relação às proporções de folha:colmo do capim-braquiária durante as épocas das águas e de seca, verificou-se que houve diferenças entre épocas e tratamentos, com a predominância de folhas sobre colmo já a partir da segunda época de avaliação (Tabela 3). A menor razão folha:colmo encontrada na primeira época de avaliação pode ser atribuída ao longo período de descanso (11 meses), imposto a pastagem, para realização deste primeiro corte, visando uma melhor reimplantação do experimento.

Tabela 3. Razão folha:colmo de capim-braquiária em monocultivo, adubada com nitrogênio e em consórcio com leguminosas

\begin{tabular}{lcccc}
\hline \multirow{2}{*}{ Tratamentos } & \multicolumn{4}{c}{ Épocas } \\
\cline { 2 - 5 } & Águas/09 & Seca/09 & Águas/10 & Seca/10 \\
\hline capim-braquiária sem intervenção & $0,87^{\mathrm{Ab}}$ & $1,18^{\mathrm{Ba}}$ & $1,04^{\mathrm{Ba}}$ & $1,04^{\mathrm{Ba}}$ \\
capim-braquiária sem N & $0,83^{\mathrm{Ac}}$ & $1,34^{\mathrm{Aa}}$ & $1,01^{\mathrm{Bb}}$ & $1,08^{\mathrm{Bb}}$ \\
capim-braquiária com N & $0,82^{\mathrm{Ab}}$ & $1,00^{\mathrm{Da}}$ & $1,01^{\mathrm{Ba}}$ & $1,00^{\mathrm{Ba}}$ \\
capim-braquiária + estilosantes CG & $0,79^{\mathrm{Ac}}$ & $1,09^{\mathrm{Ca}}$ & $1,07^{\mathrm{Ba}}$ & $1,07^{\mathrm{Ba}}$ \\
capim-braquiária + mix soja p. & $0,82^{\mathrm{Ac}}$ & $1,12^{\mathrm{Ba}}$ & $1,08^{\mathrm{Ba}}$ & $1,09^{\mathrm{Ba}}$ \\
capim-braquiária + soja p. & $0,79^{\mathrm{Ac}}$ & $1,07^{\mathrm{Cb}}$ & $1,13^{\mathrm{Aa}}$ & $1,14^{\mathrm{Aa}}$ \\
capim-braquiária + mix araquis & $0,93^{\mathrm{Ac}}$ & $1,18^{\mathrm{Ba}}$ & $1,06^{\mathrm{Bb}}$ & $1,09^{\mathrm{Bb}}$ \\
Média das Épocas & $0,84^{\mathrm{b}}$ & $1,15^{\mathrm{a}}$ & $1,06^{\mathrm{a}}$ & $1,08^{\mathrm{a}}$ \\
\hline CV $(\%)$ & & $11,86^{*}$ & $12,28^{* *}$ \\
\hline
\end{tabular}

Médias seguidas de letras maiúsculas nas colunas e minúsculas nas linhas não diferem entre si pelo teste Scott-Knott $(\mathrm{P}>0,05)$.

*CV (coeficiente de variação) dos tratamentos, **CV das épocas.

N, estilosantes CG, mix soja p. e mix arachis: Nitrogênio, Stylosantes cv. Campo Grande, Calopogonium mucunoides + Neonotonia. Wightii, Arachis pintoi cv. Belmonte + Stylosantes cv. Campo Grande, respectivamente.

A baixa razão de folha:colmo obtida em todos os tratamentos indica que o intervalo de cortes adotado nesse trabalho pode ser considerado alto para o capim-braquiária, mas mostrou-se eficiente para manutenção da maioria das leguminosas utilizadas no consórcio. Em geral, houve menor proporção de folha, principalmente nas épocas das águas, demonstrando o 
padrão de alongamento do colmo, bem característico da B. decumbens, durante a estação de crescimento.

A razão folha:colmo média de 1,04 obtida neste trabalho foi superior aos resultados apresentados por Almeida et al. (2003), para a época das águas $(0,70)$ e inferior para época de seca $(1,50)$. Entretanto, a diferença obtida, pode ser devida ao intervalo de cortes adotado (03 meses nas duas épocas), sendo este superior ao deste trabalho para época das águas e inferior para época de seca. Portanto, pode-se afirmar que o intervalo e altura de cortes, adotado para o capim-braquiária com e sem consórcio com leguminosas, estava adequado para o período das águas e pode ser diminuído durante a época de seca.

O alongamento de colmo foi mais acentuado no tratamento com adubação nitrogenada. Magalhães et al. (2007) afirmaram que a produção de colmos do capim-braquiária adubado com $\mathrm{N}$ aos 28 dias foi semelhante à de folhas e que o corte em idades superiores, dependendo da época do ano, poderia ocasionar aumento da proporção de colmos em relação à de folhas, em virtude do alongamento dos colmos. Isso mostra que a reposição deste nutriente eleva o acúmulo de biomassa e, portanto o manejo de pastagem deve ser mais cuidadoso, em virtude do maior crescimento da forrageira.

Durante todo o experimento, independentemente da época de avaliação, o acúmulo médio anual de forragem foi elevado (Tabela 4), e aumentou em relação aos dados observados em 2006, durante período anterior de avaliação deste mesmo experimento (VOLPE et al., 2008). Pois, tendo em vista de que se trata de continuidade do experimento, foi verificado que nas avaliações atuais houve evolução satisfatória dos consórcios com o tempo. Este resultado foi obtido, principalmente, através da ressemeadura de algumas leguminosas (estilo CG; mix soja perene, mix araquis), em 2008, com melhor manejo de implantação, e a persistência e/ou sucesso de implantação de outras, desde o início (2004).

Tabela 4. Acúmulo médio anual de biomassa pelos componentes e folhas de capimbraquiária em monocultivo, adubada com nitrogênio e em consórcio com leguminosas

\begin{tabular}{lccc}
\hline \multirow{2}{*}{ Tratamentos } & \multicolumn{3}{c}{ Variáveis avaliadas (kg/ha de biomassa seca) } \\
\cline { 2 - 4 } & Gramínea & Leguminosa & Total \\
\hline capim-braquiária sem intervenção & $10.253^{\mathrm{C}}$ & - & $10.253^{\mathrm{C}}$ \\
capim-braquiária sem N & $12.204^{\mathrm{B}}$ & - & $12.204^{\mathrm{B}}$ \\
capim-braquiária com N & $15.133^{\mathrm{A}}$ & - & $15.133^{\mathrm{A}}$ \\
capim-braquiária + estilosantes CG & $12.782^{\mathrm{B}}$ & $709^{\mathrm{B}}$ & $13.491^{\mathrm{B}}$ \\
capim-braquiária + mix soja p. & $13.533^{\mathrm{B}}$ & $2.050^{\mathrm{A}}$ & $15.583^{\mathrm{A}}$ \\
capim-braquiária + soja p. & $13.184^{\mathrm{B}}$ & $1.590^{\mathrm{A}}$ & $14.774^{\mathrm{A}}$ \\
capim-braquiária + mix araquis & $13.812^{\mathrm{B}}$ & $1.810^{\mathrm{A}}$ & $15.622^{\mathrm{A}}$ \\
\hline CV $(\%)$ & 13,21 & 20,31 & 10,71 \\
\hline
\end{tabular}

Médias seguidas das mesmas letras nas colunas não diferem entre si pelo teste Scott-Knott (P>0,05).

N, estilosantes CG, mix soja p. e mix arachis: Nitrogênio, Stylosantes cv. Campo Grande, Calopogonium mucunoides + Neonotonia. Wightii, Arachis pintoi cv. Belmonte + Stylosantes cv. Campo Grande, respectivamente. 
Para a produção média do capimbraquiária o efeito isolado da adubação química com $\mathrm{N}$ proporcionou acúmulo de biomassa significativamente maior que os demais tratamentos, enquanto o capim-braquiária sem intervenção apresentou menor acúmulo médio anual, evidenciando a falta de reposição de nutrientes.

A avaliação do acúmulo médio anual dos componentes do consórcio também permite verificar o comportamento diferenciado entre as leguminosas herbáceas. A participação da leguminosa na MS total pode ser considerada pequena, mas a utilização de algumas dessas espécies, como a soja perene, foi importante para manter a produtividade da gramínea, sem que haja necessidade de realização da adubação nitrogenada. $\mathrm{O}$ valor nutritivo da forragem é alterado em função da idade, da parte da planta, da fertilidade do solo e da época do ano, sendo isso, frequentemente, mencionado na literatura. Os resultados obtidos indicam melhor qualidade nutritiva da forragem na época das águas que na época seca, isto devido, principalmente, pela proximidade das avaliações em épocas de águas com a realização das adubações e também pelo efeito da variação ambiental ocorrida entre as épocas (Tabela 5).

Tabela 5. Médias dos teores de proteína bruta (PB), fibra em detergente neutro (FDN), fibra em detergente ácido (FDA), lignina (LIG) e digestibilidade in vitro da matéria seca (DIVMS) das lâminas foliares da gramínea e leguminosas, para as épocas de águas (2009 e 2010) e seca (2009 e 2010) de capim-braquiária em monocultivo, adubada com nitrogênio e em consórcio com leguminosas herbáceas*

\begin{tabular}{|c|c|c|c|c|c|c|c|c|c|c|}
\hline \multirow{2}{*}{ Tratamentos } & \multicolumn{5}{|c|}{ Águas (g/kg) } & \multicolumn{5}{|c|}{ Seca $(g / k g)$} \\
\hline & $\mathrm{PB}$ & FDN & FDA & LIG & DIVMS & PB & FDN & FDA & LIG & DIVMS \\
\hline $\begin{array}{l}\text { capim-braquiária } \\
\text { sem intervenção }\end{array}$ & $69^{\mathrm{D}}$ & $700^{\mathrm{A}}$ & $345^{\mathrm{A}}$ & $258^{\mathrm{A}}$ & $670^{\mathrm{B}}$ & $61^{\mathrm{B}}$ & $702^{\mathrm{A}}$ & $352^{\mathrm{A}}$ & $261^{\mathrm{A}}$ & $630^{\mathrm{C}}$ \\
\hline $\begin{array}{l}\text { capim-braquiária } \\
\text { sem } \mathrm{N}\end{array}$ & $69^{\mathrm{D}}$ & $695^{\mathrm{A}}$ & $316^{\mathrm{B}}$ & $243^{\text {B }}$ & $731^{\mathrm{A}}$ & $63^{\mathrm{B}}$ & $679^{\mathrm{B}}$ & $331^{\mathrm{B}}$ & $247^{\mathrm{B}}$ & $671^{\mathrm{B}}$ \\
\hline $\begin{array}{l}\text { capim-braquiária } \\
\text { com } \mathrm{N}\end{array}$ & $105^{\mathrm{A}}$ & $689^{\mathrm{B}}$ & $328^{\mathrm{B}}$ & $260^{\mathrm{A}}$ & $693^{\mathrm{A}}$ & $74^{\mathrm{A}}$ & $659^{\mathrm{C}}$ & $315^{\mathrm{C}}$ & $265^{\mathrm{A}}$ & $629^{C}$ \\
\hline $\begin{array}{l}\text { capim-braquiária } \\
\text { + estilosantes } \\
\text { CG }\end{array}$ & $87^{\mathrm{C}}$ & $688^{\mathrm{B}}$ & $338^{\mathrm{B}}$ & $228^{\mathrm{B}}$ & $718^{\mathrm{A}}$ & $60^{\mathrm{B}}$ & $677^{\mathrm{B}}$ & $305^{\mathrm{C}}$ & $238^{\mathrm{B}}$ & $670^{\mathrm{B}}$ \\
\hline $\begin{array}{l}\text { capim-braquiária } \\
+ \text { mix soja p. }\end{array}$ & $94^{\mathrm{B}}$ & $690^{\mathrm{B}}$ & $339^{\mathrm{B}}$ & $243^{\text {B }}$ & $689^{\mathrm{A}}$ & $70^{\mathrm{A}}$ & $654^{\mathrm{C}}$ & $316^{\mathrm{C}}$ & $236^{\mathrm{B}}$ & $658^{\mathrm{B}}$ \\
\hline $\begin{array}{l}\text { capim-braquiária } \\
+ \text { soja p. }\end{array}$ & $84^{C}$ & $682^{\mathrm{C}}$ & $331^{\mathrm{B}}$ & $233^{\mathrm{B}}$ & $699^{\mathrm{A}}$ & $74^{\mathrm{A}}$ & $630^{\mathrm{D}}$ & $263^{\mathrm{D}}$ & $238^{\mathrm{B}}$ & $681^{\mathrm{A}}$ \\
\hline $\begin{array}{l}\text { capim-braquiária } \\
+m i x \text { arachis }\end{array}$ & $93^{\mathrm{B}}$ & $695^{\mathrm{A}}$ & $333^{\mathrm{B}}$ & $231^{\mathrm{B}}$ & $705^{\mathrm{A}}$ & $72^{\mathrm{A}}$ & $647^{\mathrm{C}}$ & $276^{\mathrm{D}}$ & $231^{\mathrm{B}}$ & $684^{\mathrm{A}}$ \\
\hline $\mathrm{CV}(\%)$ & 6,43 & 11,02 & 10,05 & 7,88 & 6,96 & 8,94 & 13,87 & 11,89 & 7,90 & 7,55 \\
\hline
\end{tabular}

Médias seguidas das mesmas letras na coluna não diferem entre si pelo teste Scott-Knott $(\mathrm{P}>0,05)$.

*Resultados com média ponderada das lâminas foliares do capim-braquiária e planta inteira das leguminosas.

N, estilosantes CG, mix soja p. e mix arachis: Nitrogênio, Stylosantes cv. Campo Grande, Calopogonium mucunoides + Neonotonia. Wightii, Arachis pintoi cv. Belmonte + Stylosantes cv. Campo Grande, respectivamente. 
O teor de PB foi superior para o capimbraquiária que recebeu adubação química nitrogenada durante as avaliações ocorridas nas épocas das águas (Tabela 5). Resultado semelhante ao encontrado nesse experimento foram descritos por Oliveira et al. (2010), que ao avaliarem concentrações de $\mathrm{PB}$ na biomassa seca do capim-braquiária submetidos a aplicação de níveis de doses de nitrogênio, obtiveram teores de $\mathrm{PB}$ variando de 72 a $180 \mathrm{~g} / \mathrm{kg}$.

É importante salientar que os teores médios de proteína bruta nos tratamentos com $\mathrm{N}$ ou com consórcio com leguminosas nas épocas de avaliações, tanto no período das águas quanto no seco, foi superior ao nível crítico de $70 \mathrm{~g} / \mathrm{kg}$ para o atendimento das necessidades nutricionais dos microrganismos ruminais, segundo Minson e Wilson (1994). Na ausência de adubação nitrogenada e nos tratamentos em que não houve participação das leguminosas, que inclui o capim-braquiária + estilosantes CG no período seco, as concentrações de PB foram inferiores a este valor considerado crítico.

Para o teor de FDN na biomassa seca a adubação com $\mathrm{N}$ ou o consórcio com leguminosas proporcionaram resposta significativas para a redução dessa variável qualitativa, em até $10 \%$ em comparação ao capim-braquiária sem intervenção. De acordo com Lima et al. (2002), a FDN apresenta relação inversamente proporcional à densidade energética da dieta, e valores de FDN acima de $600 \mathrm{~g} / \mathrm{kg}$ correlacionam-se negativamente com consumo de forragem.

Costa et al. (2009), avaliando doses de nitrogênio na composição bromatológica do capim-marandu em estágio moderado de degradação, observaram redução nos teores de FDN com o aumento das doses de nitrogênio, de modo que os resultados ajustaram-se ao modelo linear de regressão. Oliveira et al. (2010) verificaram que a aplicação de nitrogênio em doses crescentes até $150 \mathrm{~kg} / \mathrm{ha} /$ ano influencia os teores de FDN, porém, a partir desse ponto, o aumento das doses de nitrogênio não mais proporciona variação dos teores de FDN no capim-braquiária em recuperação.

Para o teor de fibra em detergente ácido (FDA), que inclui celulose e lignina, a inclusão das adubações, mesmo sem $\mathrm{N}$, e dos consórcios foram suficientes para redução do valor em relação ao resultado do capim-braquiária sem intervenção. Os teores de FDA obtidos neste trabalho, utilizando-se dose menos de nitrogênio, foram inferiores aos apresentados por Oliveira et al. (2010), 450 a $395 \mathrm{~g} / \mathrm{kg}$, que observaram diminuição nos valores desta fibra somente conforme aumentavam-se as doses de nitrogênio.

Esse decréscimo é considerado importante, pois o elevado teor de FDA indica a baixa digestibilidade do alimento. Esse comportamento pode ser observado no capim-braquiária sem intervenção, e durante a época de seca no capim-braquiária com $\mathrm{N}$. A possível causa desse decréscimo na digestibilidade do capim-braquiária com aplicação de $\mathrm{N}$ pode ser devido ao aumento de tecidos lignificados nas plantas durante esse período de avaliação.

Os resultados, também permitem verificar que a utilização de algumas leguminosas herbáceas pode contribuir para melhoria da qualidade da dieta dos animais em pastejo. As forragens provenientes dos consórcios não apresentaram diferença, na época seca, para aquelas que receberam reposição nitrogenada, principalmente em relação aos teores de PB e FDN, e ainda revelaram menores valores para lignina 
e maiores para digestibilidade, sendo também superiores qualitativamente aos demais tratamentos sem leguminosas.

A utilização das leguminosas herbáceas na recuperação de pasto de capimbraquiária degradados sem utilização de adubos nitrogenados mostra-se viável, pois favorece o acúmulo de forragem e a qualidade da gramínea, com destaque para os coquetéis de leguminosas.

\section{REFERÊNCIAS}

ALMEIDA, R.G.; EUCLIDES,V.P.; NASCIOMENTO JUNIOR, D.; MACEDO, M.C.M.; FONSECA, D.M.; BRANCIO, P.A.; BARBOSA, R.B. Consumo, Composição Botânica e Valor Nutritivo da Dieta de Bovinos em Pastos Tropicais Consorciados sob Três Taxas de Lotação. Revista Brasileira de Zootecnia, v.32, n.1, p.29-35, 2003.

BARCELLOS, A.O. RAMOS, A.K.B.; VILELA, L.; MARTHA JUNIOR, G.B. Sustentabilidade da produção animal baseada em pastagens consorciadas e no emprego de leguminosas exclusivas, na forma de banco de proteína, nos trópicos brasileiros. Revista Brasileira de Zootecnia, v.37, p.51.67, 2008.

COSTA, K.A.P.; FAQUIN, V.; OLIVEIRA, I.P.; SEVERIANO, E.C.; OLIVEIRA, M.A. Doses e fontes de nitrogênio na nutrição mineral do capim-marandu. Ciência Animal Brasileira, v.10, n.1, p.115-123, 2009.

FAGUNDES, J.L.; FONSECA, D.M.; MORAIS, R.V.; MISTURA, C.; VITOR, C.M.T; GOMIDE, J.A.; NASCIMENTO JUNIOR, D.; SANTOS, M.E.R.; LAMBERTUCCI, D.M. Avaliação das características estruturais do capim-braquiária em pastagens adubadas com nitrogênio nas quatro estações do ano. Revista

Brasileira de Zootecnia, v.35, n.1, p.30-37, 2006.

FAGUNDES, J.L.; FONSECA, D.M.; GOMIDE, J.A. Acúmulo de forragem em pastos de Brachiaria decumbens adubados com nitrogênio. Pesquisa Agropecuária Brasileira, v.40, n.4, p.397-403, 2005.

FISHER, M. J.; RAO, I.M.; THOMAS, R.J. Nutrient cycling in tropical pastures, with special reference the neotropical savannas. In:

INTERNATIONAL GRASSLAND CONGRESS, 18, Winnipeg, Saskatoo, 1997. Proceedings... Winnipeg,

Saskatoo: Association Management Centre, 1997. p.371-382.

LIMA, L.G.; NUSSIO, L.G.N.; GONÇALVES, J.R.S.; SIMAS, J.M.C.; PIRES, A.V.; SANTOS, F.A.P. Fontes de amido e proteína para vacas leiteiras em dietas à base de capim elefante. Scientia Agricola, v.59, n.1, p.19-27, 2002.

MACHARIA, P.N.; KINYAMARIO, J.I.; EKAYAT, W.N.;

GACHENE,C.K.K.; MUREITHI,J.G.

Evaluation of forage legumes for introduction into natural pastures of semi-arid rangelands of Kenya. Grass and Forage Science, v.65, p.456-462, 2010.

MAGALHÃES, A.F.; PIRES, A.J.V.; CARVALHO, G.G.P.; SILVA, F.F.; SOUZA, R.S. Influência do nitrogênio e do fósforo na produção do capimbraquiária. Revista Brasileira de Zootecnia, v.36, n.5, p.788-795, 2007.

MINSON, J.D.; WILSON, J.R. Prediction of intake as element of forage quality. In: FAHEY JR., G.C.; COLLINS, M.; MERTENS, D.R. 
(Eds.). Forage quality, evaluation and utilization. Madison: American Society of American, 1994. p.533-563.

OLIVEIRA, D.A.; BONFIM-SILVA, E.M.; SILVEIRA, C.P.; MONTERO, F.A. Valor nutritivo do capimbraquiária no primeiro ano de recuperação com aplicações de nitrogênio e enxofre. Revista Brasileira de Zootecnia, v.39, n.4, p.716-726, 2010.

PACIULLO, D.S.C.; AROEIRA, L.J.M.; ALVIM, M.J.; CARVALHO, M.M. Características produtivas e qualitativas de pastagem de braquiária em monocultivo e consorciada com estilosantes. Pesquisa Agropecuária Brasileira, v.38, n.3, p.421-426, 2003.

PARIS, W.; CECATO, U.; MARTINS, E.N.; LIMÃO, V.A.; OLIVEIRA, E. Estrutura e valor nutritivo da pastagem de Coastcross consorciada com Arachis pintoi, com e sem adubação nitrogenada. Revista Brasileira de Saúde e Produção Animal [online], v.10 n. 3, p. 513-524, 2009.

PAULINO, V. T.; COLOZZA, M. T.; OTSUK, I. P. Respostas de Stylosanthes capitata Vogel à aplicação de nutrientes e doses de calcário em solo de cerrado. Boletim de Indústria Animal, v.65, n.4, p.275-281, 2008.
RIBEIRO JÚNIOR, J.I. Análises estatísticas no SAEG. Viçosa: Universidade Federal de Viçosa, 2001. $301 p$.

SILVA, S.C.da; NASCIMENTO JÚNIOR, D. Avanços na pesquisa com plantas forrageiras tropicais em pastagens: características morfofisiológicas e manejo do pastejo. Revista Brasileira de Zootecnia, v.36, p.121-138, 2007. Supl. especial.

SILVA, D.J.; QUEIROZ, A.C. Análises de alimentos: métodos químicos e biológicos. 3.ed. Viçosa, MG:

Universidade Federal de Viçosa, 2002. $235 p$.

VOLPE, E.; CARDOSO, S.; ZAGO, V.C.P. Recuperação de pastagem com calagem, adubação e estabelecimento de leguminosas. In: SEMINÁRIO DE AGROECOLOGIA DE MATO GROSSO DO SUL, 2., 2008, Dourados. Anais... Dourados: Embrapa Agropecuária Oeste, 2008 v.3, n.2, 2008.

Data de recebimento: 18/03/2013

Data de aprovação: 02/12/2013 